\title{
Effects of low and high levels of moderate hypoxia on anaerobic energy release during supramaximal cycle exercise
}

\author{
Yuji Ogura • Shizuo Katamoto • Jin Uchimaru • \\ Kohei Takahashi $\cdot$ Hisashi Naito
}

Published online: 26 August 2006

(C) Springer-Verlag 2006

\section{Erratum to: Eur J Appl Physiol DOI 10.1007/s00421-006-0214-9}

Unfortunately several of the author's corrections were not carried out. The main correction is specified in the following. Other corrections which do not affect the scientific content of the article are not shown here.

The reference to the following article should have been deleted:

Calbet JA, Boushel R, Radegran G, Sondergaard H, Wagner PD, Saltin B (2003a) Determinants of maximal oxygen uptake in severe acute hypoxia. Am $\mathrm{J}$ Physiol Regul Integr Comp Physiol 284:R291-R303

The online version of the original article can be found at http://dx.doi.org//10.1007/s00421-006-0214-9.

Y. Ogura $(\bowtie) \cdot$ S. Katamoto · J. Uchimaru •

K. Takahashi $\cdot$ H. Naito

Department of Exercise Physiology,

School of Health and Sports Science, Juntendo University,

1-1 Hiragagakuendai, Inba, Chiba 270-1695, Japan

e-mail: yuji-ogura@sakura.juntendo.ac.jp 